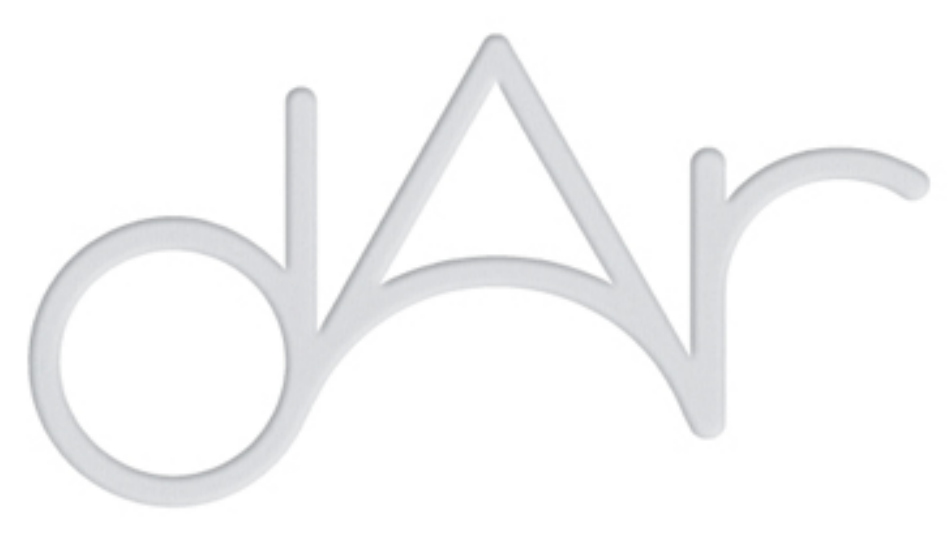

Imágenes del cuerpo en el día a día de al-Andalus

Autor(es): $\quad$ Gómez Martínez, Susana

Publicado por: Centro de Estudos em Arqueologia, Artes e Ciências do Património

URL

persistente: URI:http://hdl.handle.net/10316.2/39059

DOI: $\quad$ DOI:http://dx.doi.org/10.14195/2182-844X_2_1

Accessed : $\quad$ 26-Apr-2023 13:54:35

A navegação consulta e descarregamento dos títulos inseridos nas Bibliotecas Digitais UC Digitalis, UC Pombalina e UC Impactum, pressupõem a aceitação plena e sem reservas dos Termos e Condições de Uso destas Bibliotecas Digitais, disponíveis em https://digitalis.uc.pt/pt-pt/termos.

Conforme exposto nos referidos Termos e Condições de Uso, o descarregamento de títulos de acesso restrito requer uma licença válida de autorização devendo o utilizador aceder ao(s) documento(s) a partir de um endereço de IP da instituição detentora da supramencionada licença.

Ao utilizador é apenas permitido o descarregamento para uso pessoal, pelo que o emprego do(s) título(s) descarregado(s) para outro fim, designadamente comercial, carece de autorização do respetivo autor ou editor da obra.

Na medida em que todas as obras da UC Digitalis se encontram protegidas pelo Código do Direito de Autor e Direitos Conexos e demais legislação aplicável, toda a cópia, parcial ou total, deste documento, nos casos em que é legalmente admitida, deverá conter ou fazer-se acompanhar por este aviso.

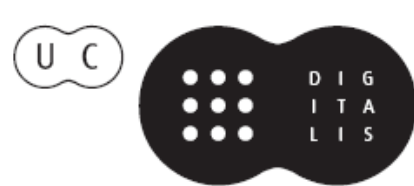




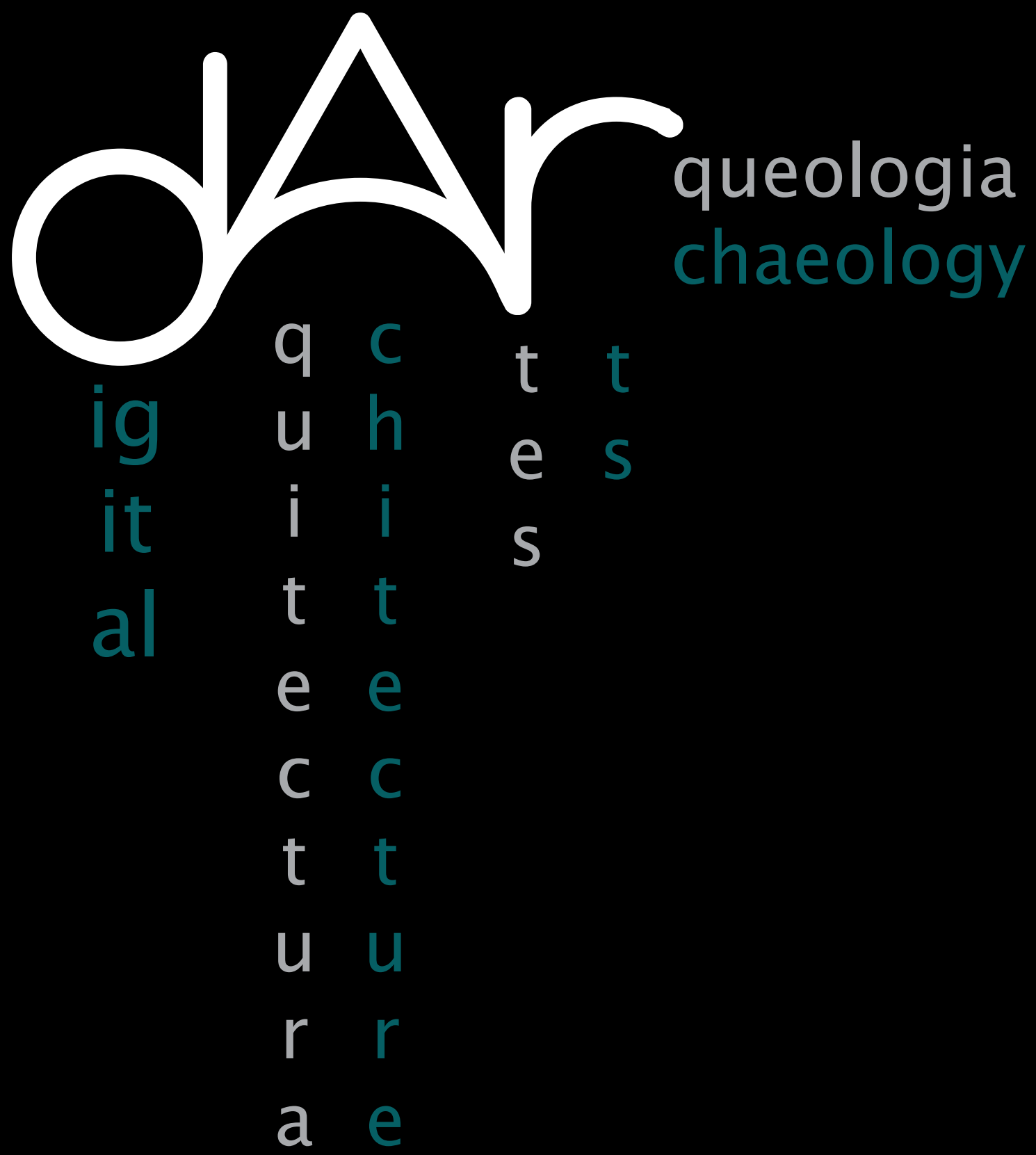




\title{
IMÁGENES DEL CUERPO EN EL DÍA A díA DE AL-ANDALUS
}

\section{Susana Gómez Martínez*}

CEAACP - Centro de Estudos em Arqueologia,

Artes e Ciências do Património

CAM - Campo Arqueológico de Mértola

\section{RESUMO}

La representación del cuerpo humano es un tema controvertido en el arte y la arqueología islámicas. Contrariamente a la creencia, popularmente bastante extendida, de que la representación de los seres vivos era prohibida en en el Islam Medieval, son muchas las representaciones que encontramos, tanto en las expresiones artísticas eruditas y palaciegas, como en las manifestaciones populares de la más diversa índole. Esta comunicación pretende aportar algunas ideas destinadas a la sistematización de la imagen humana en los objetos del día a día del medievo islámico, con especial incidencia en la cerámica del Garb al-Andalus, procurando desvendar el valor simbólico, ritual o vivencial de las representaciones.

Palavras-chave: Figura humana, Garb al-Andalus, Día a día

\begin{abstract}
The representation of the human body is a controversial theme in Islamic art and archaeology. Contrary to the wide held belief that the portrayal of the human being was not allowed in Medieval Islam, we have found many examples of artistic expressions, both regal and erudite, as well as popular examples of a diverse nature.

This paper aims to contribute some ideas to the systemization of the human image in Medieval Islamic everyday objects, especially in the ceramics from the Garb al-Andalus. It is an attempt to uncover the symbolic value of the representations as well as their experiential and ritual worth.
\end{abstract}

Keywords: Human figure, Garb al-Andalus, Daily life 


\section{LA REPRESENTACIÓN HUMANA EN EL ISLAM}

La representación de la imagen humana en el Islam es un tema controvertido que ha enfrentado a lo largo de los siglos diversas escuelas teológicas. El tema, por lo que se refiere al Islam primitivo, ha sido abordado por diversos autores, aunque en su mayor parte esgrimen argumentos ya sintetizados, hace años, por Grabar (1996: 89 y sig., ver también Ettinhausen \& Gravar, 1996: 27-28).

Varios parajes del Corán (Alcorão, 2010: V, 90 y VI, 74) rechazan las imágenes (ansab) como obra del demonio, entendidas siempre como ídolos (Alcorão, 2010: nota 512). Más allá de cualquier problema de interpretación del libro sagrado y del significado exacto de los términos utilizados en él, resulta claro que la condena incide en la idolatría y en el peligro del politeísmo. Es en este sentido en el que debe interpretarse la destrucción de imágenes en la Meca por parte de Muhammad y el hecho de que respetase una representación de la Virgen con el Niño, indicando que las imágenes, en sí mismas, no eran objeto de rechazo. Esto llevó a Ettinhausen y Grabar (1996: 28) a considerar una actitud no iconoclasta sino anicónica en el Islam primitivo.

No obstante, el texto sagrado manifiesta alguna animadversión a la creación artística, pues sólo "Dios es creador de todo y vela por todo" (Corán: XXXIX, 62) y, por lo tanto, quien ose crear una imagen de un ser vivo, se arroga un atributo divino haciéndose merecedor de la condena eterna. Esto es lo que, en mayor medida, lleva a una desconfianza en relación a las representaciones figurativas y a que los musulmanes, desde los primeros tiempos, limiten o incluso rechacen la representación de animales o personas. Esta idea se expresa de forma vehemente en algunas tradiciones (Hadith), en su mayor parte datadas ya del siglo IX, según las cuales el artífice que imita a Dios en su virtud creadora, será llamado a dar vida a sus creaciones en el Juicio Final y, si no lo consigue, será condenado para la Ełernidad.

No obstante, también son muchos los argumentos retirados del Corán y del Hadith que justifican las representaciones como forma de glorificar la obra del Creador o, en el caso de las tradiciones, determinar en qué condiciones es lícito o no el uso de imágenes. En este sentido, lo que es claro y fácil de constatar a través de la observación de los testimonios materiales del Islam medieval es que las imágenes de animales o personas, presentes en diversas expresiones artísticas, están ausentes en los espacios de carácter religioso.

El deseo del artífice de no incurrir en la blasfemia de pretender equipararse a Allah como Creador, podría justificar el fuerte esquematismo y estilización de las representaciones figuradas en el Islam y su elevado valor simbólico. También se insiste, con frecuencia, en la influencia que el carácter de divinidad abstracta del Dios de los semitas, judíos y musulmanes, habrá tenido en la concepción esquemática y simbólica de las imágenes (Rodríguez, 2008: 77). No obstante, esta tendencia no es una innovación, ni es exclusiva de la esfera islámica en la Edad Media, lo que lleva a concluir que la estilización de seres vivos, vegetales o animales, no es una invención del Islam, pero este la llevará a su máxima expresión al otorgarle el sentido e intención, específicamente islámicos, de evitar la imitación "blasfema" de la obra del Creador (Rodríguez, 2008: 78).

De hecho, como decíamos, encontramos un gran número de representaciones humanas en el arte de los primeros siglos del Islam. No es nuestro objetivo detenernos en este aspecto, no obstante, nos es de utilidad recoger algunos ejemplos de representaciones del Oriente del Mediterráneo que nos ayudan a explicar algunos aspectos de la representación humana en al-Andalus. Se trata, en concreto, de una de las pinturas de los baños de Qusayr 'Amra (Almagro, Caballero \& Zozaya, 1975) en la que se representó al monarca en su trono entre dos flabelari, reproduciendo una iconografía muy extendida en la Antigüedad que encontramos, por ejemplo, en la Domus Aurea representando la majestad de Nerón (Zozaya, 2011). Esta composición 
tripartita, muy difundida en el arte medieval, cobra diferentes significados en la Majestas del Pantocrator cristiano y en el ejemplo islámico que mencionábamos, evidenciando la capacidad del arte medieval de reinterpretar elementos iconográficos de la Antigüedad según sus necesidades simbólicas.

Las características de esta pintura son indudablemente propias del arte bizantino de la época, de cuyos artistas se nutre. No obstante, se ha señalado también la influencia sasánida en varias representaciones del soberano (Baer, 1999 o Ettighausen \& Grabar, 1996: 65-66).

Este es un ejemplo de cómo, en los primeros siglos del Islam, se configura una iconografía palatina, erudita, en la que están presentes las figuras humanas, y que adapta elementos tomados de los territorios que va ocupando, interpretándolos según sus necesidades.

\section{LA FIGURA HUMANA EN AMBIENTE ERUDITO O PALATINO DE AL-ANDALUS}

La llegada de los Omeyas a la Península Ibérica trajo consigo la introducción de nuevos elementos iconográficos en las creaciones artísticas de la Antigüedad Tardía. Es de suponer que las formulaciones que se configuraron en la zona siriopalestina en los dos primeros siglos del Islam llegarían, en mayor o menor medida, a al-Andalus $y$, de hecho, se plasmaron en la simbiosis que manifiestan los testimonios artísticos más antiguos, de los que la mezquita de Córdoba es el exponente máximo. No obstante, desconocemos la existencia de representaciones humanas en el arte oficial durante el periodo emiral (siglos VIII y IX), sin poder determinar si no se han conservado, o si realmente no existieron. Sí que conocemos representaciones de animales (leones y grifos) como, por ejemplo, el conjunto escultórico de Lisboa, formado por el friso ornamental y el pilar de Chelas y el pilar de la Casa dos Bicos, que puede remontar al siglo IX y que refleja importantes influencias de los palacios omeyas del Próximo Oriente (Real, 1998: 82-85).
Las más antiguas representaciones humanas conservadas de al-Andalus se fechan en época califal. Son bien conocidas las expresiones artísticas palatinas, ejecutadas en mármol, seda, marfil y cerámica, que han sido objeto de numerosos estudios por parte de historiadores del arte por su excepcional riqueza, tanto en materiales como en ejecución técnica, por su equilibrada composición y por la belleza de los temas representados.

Es rara la presencia de personas en la decoración arquitectónica de al-Andalus. Una notable excepción es el capitel de los músicos, proveniente de Córdoba, de finales del siglo $X$, que presenta, en cada uno de sus cuatro lados, tañedores tocando diferentes instrumentos de la familia del 'ud, antecedente del actual laúd (Carpio Dueñas, 2001:135). Otra rara excepción, la encontramos en una pila de mármol de Játiva del siglo XI (Dodds, 1992) donde aparecen diversas escenas de carácter "cortesano": un conjunto de músicos, un bebedor con un sirviente, escenas de juegos entre las cuales una lucha con garrote, una procesión con ofrendas, un ama de cría, leones, lanceros y pavos reales con los cuellos entrelazados.

Sin embargo, es frecuente la presencia de figuras humanas en la eboraria del siglo $X$ e inicios del XI, el ámbito más estudiado desde el punto de vista de la Historia del Arte (una síntesis reciente en Silva, 2013). Está lejos de nuestra intención, hacer un corpus sistemático de las representaciones humanas en este material, o de las interpretaciones que se han elaborado de los distintos temas iconográficos o de su significado socio-político (Prado-Villar, 1997), pero señalaremos algunos motivos que podemos conectar con el ejemplo oriental que mencionamos anteriormente, atestiguando la relación existente entre la iconografía de los Omeyas de Oriente y de Occidente. Así, en la Arqueta de Leyre, realizada en Córdoba a inicios del siglo XI para Abd al-Malik, hijo de Almanzor, podemos identificar un soberano barbudo, dotado de anillo de sello, que sostiene una botella y una rama o racimo, con dos servidores, uno a cada lado, el de la 
derecha con un abanico y una botella o esenciero, y el de la izquierda con un mosqueador (Holod, 1992: 198-201) semejante a la representación del fresco de Qusayr 'Amra.

También encontramos ejemplos iconográficos antropomorfos de enorme valor en los bordados en brocado de seda, conocido como tiraz. Dentro de este capítulo, llamamos la atención para una pieza singular, la yuba funeraria del Monasterio de Oña (Casamar \& Zozaya, 1991), un auténtico repertorio iconográfico califal en el que se encuentran dos elementos de carácter antropomorfo: la sirena y el sedente. La primera se representa en su forma clásica, con cabeza de mujer y cuerpo de ave, y no en la formulación medieval tardía con cuerpo de pez. La segunda figura humana corresponde a una representación del soberano sentado en su trono, donde volvemos a encontrar, entre otros atributos regios, algunos de los que exhibe el soberano de la Arqueta de Leyre: el anillo de sello y la botella (fig. 1). Este personaje se ha identificado con el primero

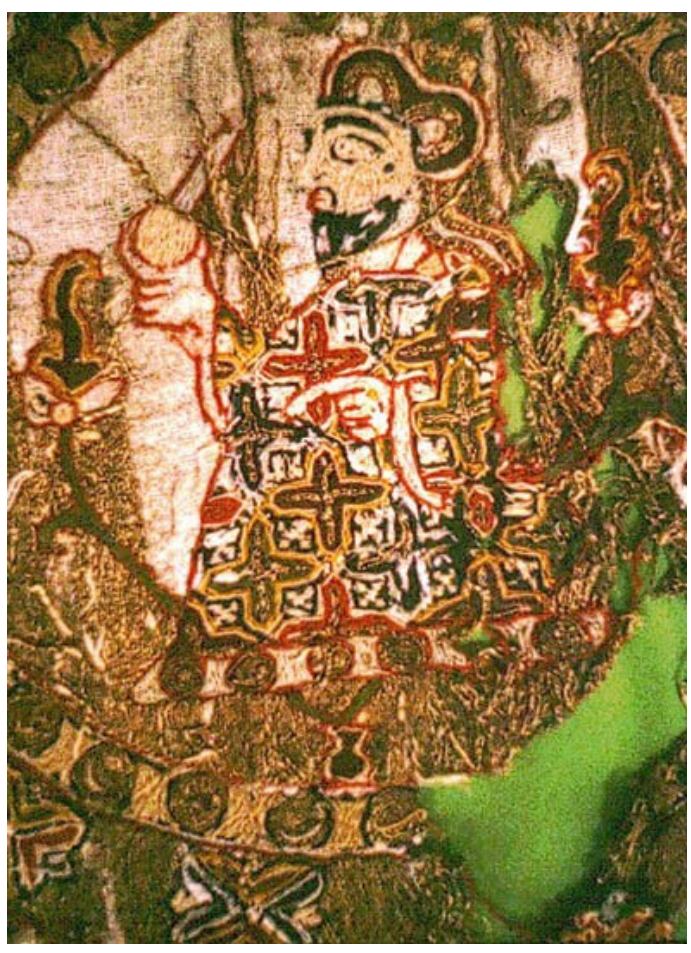

Fig. 1 - Figura del soberano en la Tela de Oña. Imagen cedida por Juan Zozaya. de los Omeyas, Mu'awiyya, por Juan Zozaya (2011) y con Abd al-Rahman l, el primer Omeya andalusí, por Manuela Marín, que recoge una descripción detallada de este soberano del que se destaca la barba negra y el lunar en la cara, como en el soberano sedente de Oña (Marín, 2011).

Podemos deducir de la comparación de estas dos figuras que la presencia de la botella no es banal sino que responde a un elemento de identificación del soberano, como expone Juan Zozaya para el cual la redoma de cristal "simboliza, no el amor hacia el vino (acusación típica anti-omeya) sino el poder para llenar o vaciar una copa, que igual que un odre, simboliza el poder divino de llenar un contenedor con vida, o vaciarlo" (Zozaya, 201 1: 12). Sería en este sentido, por lo tanto, como habría que interpretar otras escenas "cortesanas" que aparecen en los marfiles califales, por ejemplo en la ya mencionada Arqueta de Leyre, donde aparecen otros personajes con el jarro de la vida, además del soberano ya descrito.

Estas representaciones en marfil o seda surgen en objetos de lujo, de ambientes aristocráticos palatinos. Se trata de obras encomendadas dentro de la esfera de la corte califal y ejecutadas por artífices de su ámbito de influencia. Cabría pensar, por lo tanto, que se trata de una iconografía erudita y palaciega, propia de las elites políticas y militares pero que no llegó necesariamente a difundirse por el conjunto de al-Andalus.

Sin embargo, varias piezas de cerámica confirman la presencia de este registro iconográfico en un material más popular y accesible al común de la población. Una de las piezas más conocidas es la botella con un conjunto de seis músicos de Córdoba (Rosselló, 1992) que se ha interpretado como una escena palatina que reproduce el modo de vida de la corte omeya, semejante a las que aparecen, repetidamente, en los marfiles de los siglos $X$ y $\mathrm{XI}$ y también en las piezas en mármol de Córdoba y Játiva. Representaciones de músicos aparecen en otras vasijas de la serie de "verde y morado" de 
Córdoba (Aparicio \& Cano, 2011) y Évora (información amablemente cedida por José Santos). El significado de estas escenas "cortesanas" ha sido interpretado por varios autores como representaciones simbólicas del poder (Doods, 1992).

Uno de los ejemplos más apurados del paso de estos temas simbólicos desde los materiales nobles a la cerámica, lo encontramos en un ataifor decorado en "verde y morado" encontrado en Palmela de inicios del siglo XI (Fernandes, 1999). A pesar de encontrarse incompleto, podemos identificar sin dificultad una figura humana con los atributos del soberano que aparecen también en el tejido de Oña y en la Arqueta de Leyre: el anillo de sello y la botella con el líquido de la vida (fig.2).

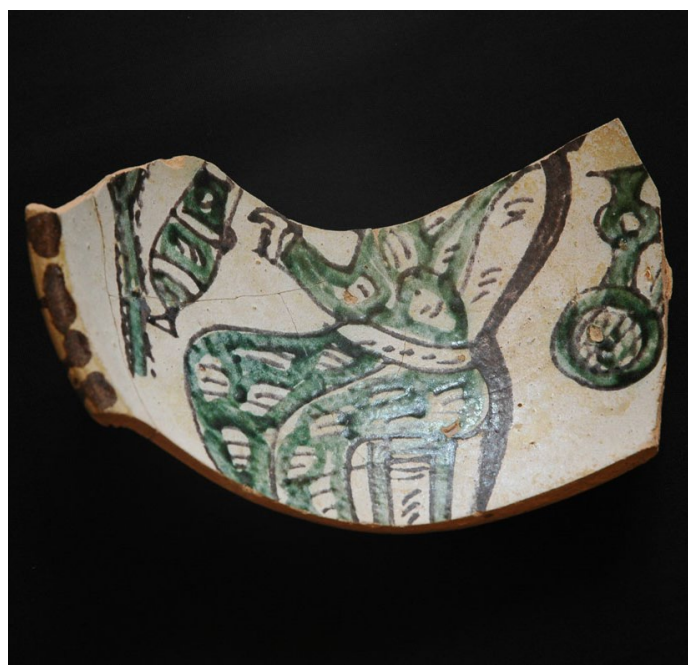

Fig.2 - Representación del soberano en un ataifor encontrado en Palmela.

Otro ejemplo de transposición de esta formulación erudita para la cerámica lo encontramos en un ataifor encontrado en Benetússer, cerca de Valencia (Escribá, 1990) con la misma cronología (Soler, 2001). En él encontramos un personaje sin tocado ni barba que bebe de una botella.

Se han encontrado otros ejemplares de cerámica con temas antropomórficos ejecutados en verde y morado en Madinat al-Zahra e llbira (Gómez Moreno, 1951: 312; Retuerce \& Zozaya, 1986; Cano, 1996) y Mértola (Gómez, 1994, Gómez, 2014), pero se trata de fragmentos muy pequeños y resulta difícil reconocer las figuras completas y su significado iconográfico.

De forma genérica, se ha atribuido a la cerámica decorada en verde y morado un elevado valor simbólico como expresión del poder califal y como forma de propaganda de los Omeyas (Barceló, 1993; Acién, 1996). Este tipo de cerámica siguió fabricándose durante el período de los Reinos de Taifa, y su producción estuvo ampliamente difundida por diversos territorios de alAndalus (Bazzana, Lemoine \& Picon, 1986), lo cual debe relacionarse con el fenómeno, bien conocido, de que los Reyes de Taifas siempre justificasen su poder como subordinado a la legitimidad de los Omeyas.

Se podría argumentar que se trata de producciones palatinas que fueron ofrecidas a los aristócratas de la periferia en época califal, o promovidas por los reyes de taifas dentro del ámbito de su corte. No obstante, la muy generalizada difusión de la cerámica de verde y morado, especialmente a partir del siglo XI, indica que este tipo de objetos no serían exclusivos de ambientes palatinos, por lo que tendrían una poderosa eficacia como vehículos de propaganda.

\section{REPRESENTACIONES ANTROPOMORFAS EN LOS SIGLOS XII Y XIII}

A partir del siglo XII la representación de figuras humanas se hace menos frecuente en los materiales más nobles, aunque no desaparece completamente. De hecho volvemos a encontrar músicos representados en vasijas de cerámica en Murcia, ya no sobre cerámica decorada en verde y morado, sino sobre cerámica pintada en negro y esgrafiada (Navarro, 1980 y 1986), un tipo de cerámica que se ha relacionado también con la propaganda política de Ibn Hud, partidario de los abasidas que utilizaban el negro ostensivamente como identificador político y religioso (Acién, 1996; Guichard, 1990: T. 1, 141).

Es a partir del siglo XII cuando encontramos un tema iconográfico antropomorfo nuevo, 
la hamsa, popular e incorrectamente conocida como "Mano de Fátima" (Maçarico, 201 1). Se trata de una mano abierta que simboliza el número cinco (hamsa en árabe) de fuerte valor simbólico, ya que cinco son los pilares del Islam, cinco las oraciones que el fiel debe realizar diariamente, etc. (Zozaya, 2011). Se trata, por tanto, de la representación figurada de la idea abstracta de la bendición divina, que encontramos en diversos soportes. En cerámica aparece en un gran ataifor decorado en verde y morado de Alarcos (Retuerce \& Juan, 1999), en jarras esgrafiadas de Sagunto, Murcia, Cieza, Lorca, Almería y Ceuta (Navarro, 1986: 7984) y en tinajas con la mano estampada mediante una matriz (Gómez, 2011: 30, ver fig. 3), a título de ejemplo.

Este símbolo adquirió, muy temprano, un

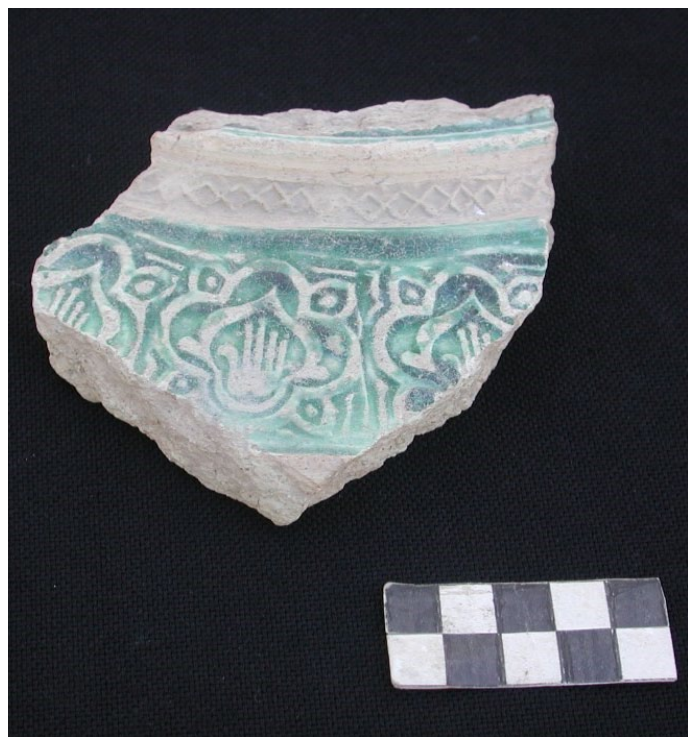

Fig.3 - Fragmento de tinaja con un motivo estampillado representando la hamsa.

fuerte valor profiláctico para prevenir el mal de ojo. No son raros los ejemplos de colgantes en hueso con forma de mano, encontrados en diversos yacimientos de al-Andalus en contextos de la segunda mitad del siglo XII y primera mitad del XIII (Gómez, 2011: 49). La fuerza protectora de este símbolo se ha mantenido hasta nuestros días en el Norte de África, más allá del aprovechamiento turístico de que actualmente es objeto.
Por lo que se refiere a las representaciones de figuras completas de personas, se han encontrado en el Garb al-Andalus tres figuras de jinetes sobre sus caballos representados sobre placas de plomo recortadas. La forma de montar y el gesto del caballero sugieren una escena de montería con halcón. Esta imagen, frecuente en la Antigüedad Tardía, como podemos observar, por ejemplo, en los mosaicos del siglo VI de Mértola (Lopes, 2003: 110-112), revestida de un nuevo significado, fue asimilada por el mundo islámico. A título de ejemplo, jinetes con su caballo aparecen en la cerámica vidriada polícroma en Irán y en Túnez en el siglo X, y halconeros a caballo en cerámica de tipo "minai" de Persia en el siglo XIII (Soustiel, 1985: 22, 58, 158, 95). La figura del halconero también es frecuente en otros materiales; podemos encontrarla en marfil en los Botes de los museos Victoria \& Albert y Louvre y en la ya mencionada arqueta de Leyre, y en tejido, en el sudario de San Lázaro de Autum (Zozaya, 2010).

De las tres placas de plomo con imagen de jinete del Garb al-Andalus, dos se han encontrado en Mértola (VV.AA., 1998: 107 y Gómez, 2011) y una en Silves (Gomes, 1998: 20; Gomes, 2000: 319). Esta última fue interpretada como una insignia de peregrino representando Santo Tomás Becket. En el caso de Mértola, una de ellas apareció en un contexto del tercer cuarto del siglo XII, por lo que nos parece poco probable que un peregrino perdiese la imagen recuerdo del santo, en un puerto musulmán, poco tiempo después de la muerte del arzobispo inglés en 1170, sobre todo teniendo en cuenta que los ejemplares de insignias de peregrino de Santo Tomás del British Museum se fechan en el siglo XIII, época de la primera referencia textual a este tipo de objetos (Tait 1955: 39). Aunque la figura del halconero ha sido considerada con frecuencia como la representación de una escena palaciega de caza, Juan Zozaya la identifica con la imagen de muyyāhid, el mártir por la fe (Zozaya, 2010).

A partir del siglo XII, aparece una tipología rara hasta entonces en cerámica: las figuras de bulto, que pueden aparecer aisladas o 


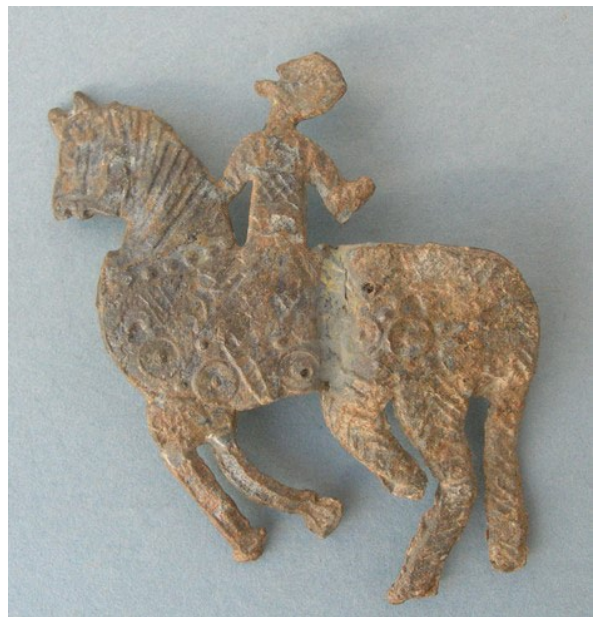

Fig.4 - Insignia de caballero.

formando parte de un objeto complejo.

Las más antiguas son dos ejemplares procedentes de Pechina (Almería) con cronología de los siglos IX-X: una tosca cabeza humana (VV.AA., 1993: 226; VV.AA., 2006: 170) y un jinete con su caballo (VV. AA., 2006:171). No tenemos muchos detalles sobre el contexto exacto de su hallazgo, aunque parecen estar asociadas a los talleres de alfarería encontrados en este yacimiento (Castillo, Martínez \& Acién, 1987) y cabría pensar que el contexto manufacturero fue el que los ocasionó.

El ejemplo más espectacular de figuras humanas de bulto es, sin duda, la pieza conocida como "Vaso de Tavira" (Maia, Maia \& Torres, 1998; Gomes, 1998; Maia, 2003a; Torres, 2004; Maia, 2004 y 2012; Rosselló, 2006 y Paulo, 2007). Se trata de un recipiente de paredes altas y diámetro considerable, con el borde formando un tubo por el que circularía agua y al que está adosado un conjunto de figuras de animales y personas (fig. 5). El grupo principal lo componen tres figuras humanas montadas a caballo: una mujer tocada con una especie de diadema, con un guerrero a cada lado, uno armado con una lanza y el otro con espada y escudo. Un tercer guerrero, a pie, está provisto con una ballesta. A su lado y siguiendo el sentido de las agujas del reloj, encontramos una tortuga, animal asociado a la longevidad, y una torre, en la que están posadas pequeñas aves, y que serviría de embudo por el que introducir el líquido. A continuación encontramos un conjunto de animales entre los que se reconoce claramente un camello, conocido como símbolo de abundancia, y un buey o toro identificado por un su cuerpo robusto y la presencia de un cencerro. Las dos figuras siguientes han desaparecido. El último conjunto de figuras corresponde a un grupo de músicos de los que se han conservado sólo dos, uno de ellos tocando un adufe o pandero cuadrado y el otro lo que parece una flauta travesera o un tambor. La pieza está plagada de detalles interesantes que nos llevaría muchas páginas describir, por eso nos referiremos únicamente a los que nos sirvan en nuestro hilo argumental.

Se han vertido varias interpretaciones para este asombroso objeto. Maria Maia (2004 y 2012), Cláudio Torres (2004) y Guillermo Rosselló (2006) lo relacionan con algún tipo de ritual de carácter matrimonial, mientras que Mário Varela Gomes (1998) y Luís Campos Paulo (2007) lo consideran una pila de abluciones destinada a incentivar la djihad. No podemos entrar en detalles sobre los argumentos de unos y otros por falta de espacio, por lo que únicamente nos pronunciaremos globalmente sobre cuál sería la hipótesis más apropiada inclinándonos por la nupcial y no por la de una pila de abluciones alusiva a la djihad, especialmente cuando esta última se justifica por un contexto cronológico y político determinado (Paulo, 2007) que no nos parece correcto.'

A los argumentos esgrimidos por unos y otros, cabría añadir dos observaciones. En primer lugar, las pilas de abluciones en cerámica que se han identificado son, en su mayor parte, piezas que imitan las tipologías de las pilas de abluciones en mármol. También se están identificando como este tipo de objetos los anteriormente conocidos como bacines o pericos en cuerda seca de época almohade. El vaso de Tavira no responde a tipologías conocidas en otros materiales que justifiquen, por esta vía, su función. Por otro lado, la representación de 
figuras humanas es especialmente evitada en espacios y contextos de cariz religioso, como veíamos anteriormente, por lo que su uso en un objeto destinado a la purificación ritual (sea o no en un contexto militar) nos parece poco plausible.

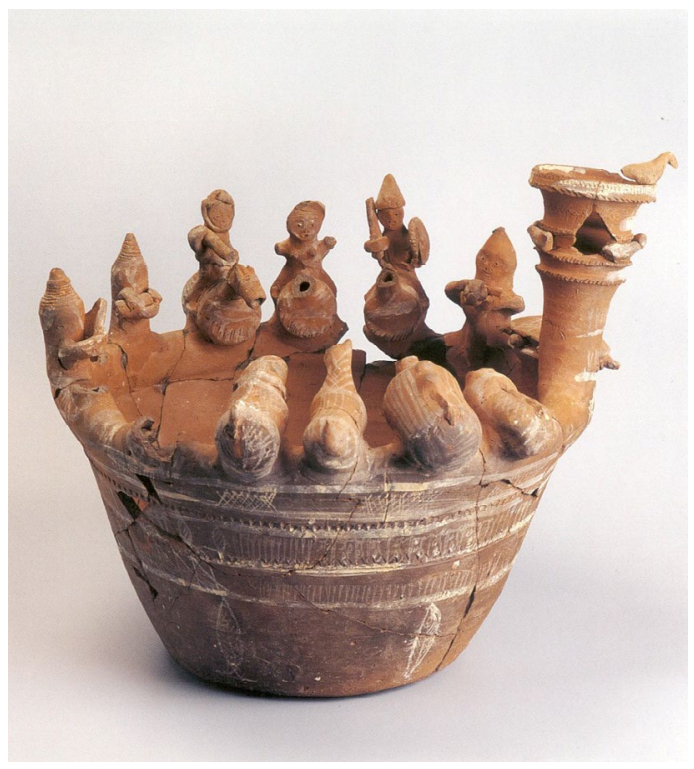

Fig.5 - Vaso de Tavira.

Nos parece indudable el cariz popular de esta pieza. La iconografía de la época en materiales nobles, aquellos en los que se suelen plasmar los programas oficiales y los símbolos de mayor relevancia religiosa, no nos ha dejado ningún objeto próximo a este. Por otro lado, no podemos considerarlo como un unicum; en varios yacimientos de al-Andalus, en contextos de los siglos XII y primera mitad del XIII, han surgido otros vasos o fragmentos, especialmente figuras: en Tavira se constata un animal que pertenecería a otra pieza de este género (Maia, 2003b); en Silves varias figuritas humanas que también estarían unidas a un recipiente mayor (información inédita amablemente cedida por Maria José Gonçalves); en Córdoba se ha encontrado la pieza de este tipo mejor conservada, después de la de Tavira (Salinas, 2012: 289-392). Tenemos noticias orales de otros ejemplares en al-Andalus y Norte de África por lo que podemos considerar que el ritual, más o menos cotidiano, al que estarían unidas estas piezas era bastante corriente.

También encontramos en los siglos XII y XIII figuritas antropomorfas exentas, sin evidencias de haber pertenecido a un recipiente. Son más habituales las representaciones zoomorfas pero se cuenta también con algunos ejemplos de figuras humanas en Almería del siglo XII y en Jaén de época almohade, (VV. AA., 2006: 173, 175, 178 y 179). En córdoba han aparecido varias representaciones antropomorfas de bulto que Elena Salinas identifica como miniaturas (Salinas, 2012: 396-402). Reconoce un jinete con su caballo y cuatro figuras humanas aisladas, una de ellas completa y ejecutada con especial cuidado y detalle (Salinas, 2012: 401). Se trata de un músico sentado, tocando un tambor, con los rasgos faciales y manos bien definidos, y varios adornos personales (collar, pendientes y turbante con broche).

La interpretación como juguetes de estas miniaturas y otras que reproducen en pequeñas dimensiones la vajilla doméstica, ha ocasionado alguna discusión. Torres Balbás (1956) relacionaba las figuras de cuadrúpedos de barro cocido de Córdoba, Almería y Granada con los juguetes que menciona un tratado de hisba de Ibn Rusd, que criticaba la costumbre de fabricar juguetes en forma de animales con motivo del año nuevo. También Al'Uabani identificaba la misma costumbre en Tremecén atribuyéndole un origen cristiano. En algunos casos podrán corresponder a silbatos con funciones apotropaicas de ahuyentar los malos espíritus (Rosselló, 2006: $24,43)$. También, tendrían estos mismos poderes profilácticos, relacionados con rituales de purificación, los elementos zoomórficos asociados a las asas de las tinajas (Torres et alii, 1996). Recientemente, en un encuentro en Alicante y Denia, Patrice Cressier y Sophie Gillote se pronunciaban a favor de la interpretación como juguetes de estos objetos. En cualquier caso, como ha señalado Cláudio Torres (2004: 3-4), el juego de los niños y la propia noción de infancia deben ser interpretados en el contexto medieval y no en función del concepto contemporáneo. 
Así, los juegos de los niños están dotados de capacidades mágicas y poderes profilácticos. Igualmente, se ha remarcado, a propósito de estas figuritas, la importancia del juego en el proceso de adiestramiento, aprendizaje y asimilación de la realidad e interacción con el medio del niño (Peral \& López, 2006: 114).

Tal vez se pueda dar la misma interpretación, a un caso raro, también encontrado en Córdoba, de configuración antropomorfa para un objeto. Se trata de un simpático tapón cilíndrico para botella, rematado con una cabeza con gorro cónico y ojos y boca pintados, y con un brazo apoyado en la cabeza y el otro doblado hacia delante. La ejecución tosca indica, una vez más, un contexto popular para este singular objeto.

Por último nos referiremos a una pieza, también rara, en la que aparecen varias figuras humanas dibujadas (fig. 6). Se trata de una cantimplora, bastante fragmentada e incompleta, sobre la cual se pintaron con óxido de manganeso motivos negros que resaltan sobre su superficie blanquecina. El objeto, de cuerpo lenticular, sin base sobre la que asentar, poseía dos asas y una boca en la parte superior. En cada lado de la pieza, se dibujaron, en varios planos sobrepuestos, un conjunto de figuras humanas de ojos almendrados, muchas de ellas incompletas. En una de las caras de la cantimplora podemos reconocer dos personajes masculinos, uno de ellos de medio cuerpo, con los brazos apoyados en las caderas, en posición desafiante, tiene barba y un yelmo cónico, relleno con puntos, a semejanza de las figuras del Vaso de Tavira. El otro personaje, también barbudo, está incompleto y con los tratos mal definidos.

El otro lado de la cantimplora, más mutilada, presenta tres figuras, dos de ellas fragmentadas. En el lado izquierdo, el personaje más completo, situado en segundo plano, presenta también casco cónico puntiagudo. En primer plano, aparece otra figura de cabeza descubierta de la que únicamente conservamos el cabello y los ojos almendrados. El dibujo del lado derecho, de trazos menos definidos, no permite una lectura clara, aunque se distinguen algunas pequeñas cabezas en las cuales ojos y boca son sugeridos con puntos.

Esta forma de cantimplora sólo se generaliza en el Garb al-Andalus a partir de finales del siglo XI, pero sobre todo durante el siglo XII, hecho que, ante la ausencia de una fecha contextual para el objeto, nos lleva a atribuir esta cronología a este artefacto.

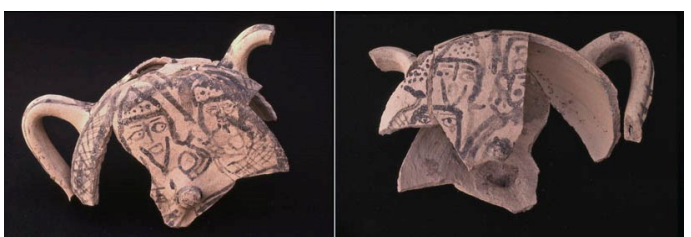

Fig.6 - Cantimplora con representaciones humanas de Silves.

Especular sobre el significado de este conjunto de figuras es bastante arriesgado. No conocemos representaciones parecidas en al-Andalus, en este o en otro material. La torpeza de los trazos y su fuerte esquematismo, en el que se aprecian algunos detalles selectivos, indica alguna espontaneidad y ausencia de modelos iconográficos previos. La presencia de los cascos nos ha llevado a pensar que se pueda tratar de guerreros que, dado el número y la sucesión de planos, parecen configurar un ejército. Intentar identificar este ejército con las huestes cruzadas que conquistaron la ciudad den 1189, fecha compatible con la cronología atribuida a esta cantimplora, sería una especulación carente de justificación. En conclusión, poco más podemos decir, salvo confirmar el cariz popular de esta representación y sospechar que su autor estaría a verter para el objeto una vivencia de los habitantes de la Silves del siglo XII.

\section{A MODO DE CONCLUSIÓN}

Recapitulando algunas de las ideas expuestas en páginas anteriores, constatamos que se conservan representaciones de la figura humana en al-Andalus por lo menos desde el siglo X. 
En época califal y taifa, surge en temas mayoritariamente conectados con los programas iconográficos eruditos, de fuerte raigambre bizantina y sasánida. Aunque es en los materiales nobles (mármol, marfil y seda), producidos y consumidos en ambientes palatinos, donde encontramos más variedad de imágenes, estas representaciones figuradas, fueron vertidas en materiales más baratos e consumidos por una gran parte de la población de al-Andalus. Así el análisis de las cerámicas de día a día de la población confirma la circulación de los programas iconográficos y propagandísticos del poder, por lo menos en los medios urbanos.

A partir del siglo XII, la representación humana de los programas iconográficos palatinos disminuye sin desaparecer, cobrando mayor expresión las representaciones simbólicas de fuerte cariz religioso como la hamsa o el muyyāhid. Por contra, las expresiones populares, reflejo de las vivencias cotidianas de la población en general, experimentan un aumento de las representaciones humanas, sobre todo de bulto. En este ámbito de lo popular y espontaneo resulta extremadamente difícil e insegura una interpretación del significado de las figuras y, no sólo por la fragmentación de la mayoría de los objetos encontrados, como también por la ausencia de referencias textuales o de información contextual clara que elucide sobre su uso.

Dado lo expuesto, tendríamos que matizar la teoría de Baer (1999) según la cual existirían dos grandes fases en la representación humana de los primeros siglos del Islam. La primera, entre el siglo VII y finales del X, adoptaría el vocabulario y las formas sasánidas y greco-romanas en un arte oficial que desea demostrar visualmente el poder del califa o decora las paredes de las sedes del poder con escenas de caza y otros pasatiempos reales. La segunda fase, entre finales del siglo X y mediados del siglo XIII, presentaría un cambio en el "vocabulario artístico" y un estilo más realista que podría estar relacionado con el ascenso de una cierta burguesía en el mundo fatimí y en la Mesopotamia del siglo XIII.
En al-Andalus, también podríamos distinguir dos fases, pero no sería en el siglo $X$, sino en la transición entre el XI y el XII, cuando se aprecien mudanzas significativas. Tal y como Baer señala, en una primera fase, entre los siglos X y XI, encontramos, sobre todo, un repertorio de carácter palatino de propaganda del poder soberano, pero que en al-Andalus no se limita a "decorar las sedes del poder". En relación a la segunda fase, los cambios sólo se producen a partir del siglo XII y los cambios no reflejan un "estilo más realista", sino un cariz popular en las representaciones, quedando para los programas iconográficos eruditos elementos simbólicos de carácter religioso.

\section{Notas}

(1) Se le atribuye a la pieza una cronología emiral incorrecta en virtud de los datos estratigráficos, las características técnicas del objeto, los paralelos ceramológicos y la propia evolución histórica de Tavira.

\section{Bibliografia}

Acién Almansa, M. (1996), Cerámica y propaganda en época almohade. Arqueologia Medieval. Porto: Edições Afrontamento. $N^{\circ} 4,183-193$.

Alcorão (2010), Alcorão Sagrado. Traducción de Prof. S. El Hayek. Oeiras: AD ASTRA ET ULTRA.

Almagro, M.; Caballero, L. \& Zozaya, J. (1975), Qusayr 'Amra. Residencia y Baños omeyas en el desierto de Jordania. Madrid: Ministerio de Asuntos Exteriores. 145 pp. + XLVIII láms.

Aparicio Sánchez, L. \& Cano Montoro, E. (2010), Fragmento cerámico con decoración antromorfa en verde y manganeso hallado en el arrabal de "El Fontanar" (Córdoba). Antiqvitas. Priego de Córdoba: Museo Histórico Municipal. № 22, 183-196. Disponible en http://dialnet.unirioja.es/servlet/ articulo? codigo $=3326516$.

Baer, E. (1999), The human figure in early islamic art: some preliminary remarks. Muqarnas. Leiden, Brill. Vol. 16, pp. 32-41.

Barceló, Miquel (1993). Al-Mulk, el verde y el blanco. La vajilla califal omeya de Madina alZahrā'. In La cerámica altomedieval en el sur de al-Andalus (291-299). Granada: Universidad de Granada.

Bazzana, A.; Lemoine, CH. \& Picon, M. (1986), 
Le problème de l'origine et de la diffusion des céramiques dites califales: recherche préliminaire. In Segundo Coloquio Internacional de Cerámica Medieval en el Mediterráneo Occidental. Toledo, 1981 (3338). Madrid: Ministerio de Cultura.

Cano Piedra, C. (1996), La cerámica verdemanganeso de Madinat al-Zahrā'. Granada: El legado andalusí.

Carpio Dueñas, J.B. (2001), Capitel con cuatro músicos. In El esplendor de los Omeyas cordobeses. Catálogo de Piezas (p. 135-136). Granada: El Legado Andalusí. ISBN 84-9320511-7. P. 168

Casamar, M. \& Zozaya, J. (1991), Apuntes sobre la yuba funeraria de la Colegiata de Oña (Burgos). Boletín de Arqueología Medieval. Madrid: Asociación Española de Arqueología Medieval. № 5, pp. 39-60.

Castillo Galdeano, F.; Martínez Madrid, R.; Acién Almansa, M. (1987), Urbanismo e industria en Bağğana. Pechina (Almería). In Il Congreso de Arqueología Medieval Española, Madrid, 1987 (Tomo II, 539-548). Madrid.

Corán (1986), El Corán. Edición preparada por Julio Cortés. Barcelona: Editorial Heder.

Doods, J. (1992), Pila de Játiva. In Al-Andalus. Las Artes Islámicas en España (261-263). Madrid: El Viso.

Escribá, F. (1990), La cerámica califal de Benetússer. Valencia: Ministerio de cultura.

Ettinghausen, R. \& Grabar, O. (1996), Arte y arquitectura del islam. 650-1250. Madrid: Ediciones Cátedra.

Fernandes, I. C. F. (1999). Uma taça islâmica com decoração antropomórfica proveniente do Castelo de Palmela. Arqueologia Medieval. Porto: Edições Afrontamento. № 6, pp. 79-99.

Gomes, M. V. (1998), Portugal islâmico. O estado da arte? Al-madan. Almada. 7, 19-20.

Gómez Martínez, S. (1994), La cerámica de verde y morado de Mértola. Arqueologia Medieval. Porto: Edições Afrontamento. №3, 113-132.

Gómez Martínez, S. (Ed.) (2011), Os Signos do Quotidiano: Gestos, Marcas e Símbolos no al-Ândalus. Catálogo da Exposição. Mértola: Campo Arqueológico de Mértola.

Gómez Martínez, S. (2014), La cerámica islámica de Mértola. Mértola: Campo Arqueológico de Mértola.

Goméz Moreno Martínez, M. (1951), El arte español hasta los almohades. Arte Mozárabe.
In Ars Hispaniae. Volumen tercero. Madrid: Editorial Plus-Ultra.

Grabar, O. (1996), La formación del Arte Islámico ( $7^{\mathrm{a}} \mathrm{Ed}$.). Madrid: Cátedra. $255 \mathrm{pp}$.

Guichard, P. (1990), Les musulmans de Valence et la reconquête : Xle - XIIle siècles. Damas: Institut Français de Damas; Paris : Adrien Maisonneuve. 2 vols.

Holod, R. (1992), Arqueta de Leyre. In Al-Andalus. Las Artes Islámicas en España (pp. 198-201). Madrid: El Viso.

Lopes, V. (2003), Mértola na Antiguidade Tardia. A topografia histórica da cidade e do seu território nos alvores do cristianismo. Mértola: Campo Arqueológico de Mértola.

Maçarico, L.F. (2011), A mão que protege e a mão que chama: orientalismo e efabulação, em torno de um objecto simbólico do Mediterrâneo. Dissertação de mestado, História, Faculdade de Ciências Humanas e Sociais, Universidade do Algarve, 2011 Disponible en https://sapientia.valg.pt/ bitstream/10400.1/3000/1/Tese_versaodefinitiv a_28marco2012\%5b1\%5d.pdf.

Maia, M. G. P. (2004), O Vaso de Tavira e o seu contexto. In Portugal, Espanha e Marrocos. O Mediterrâneo e o Atlântico. Actas do Coloquio Internacional Universidade do Algarve, Faro, Portugal, 2, 3 e 4 de Novembro de 2000 (143-166). Faro: Universidade do Algarve.

Maia, M. (2003a), Vaso de Tavira, com decoração coroplástica. In Tavira. Território e Poder ( $p$. 300). Lisboa: Museu Nacional de Arqueologia.

Maia, M. (2003b), Asa zoomórfica. In Tavira. Território e Poder (p. 301). Lisboa: Museu Nacional de Arqueologia.

Maia, M. G. P. (2012), Vaso de Tavira. Tavira: Museu Municipal de Tavira/Câmara Municipa de Tavira.

Maia, M.; Maia, M.; Torres, C. (1998), Vaso. In Portugal Islâmico. Os últimos sinais do Mediterrâneo (p. 99). Lisboa: Museu Nacional de Arqueologia.

Marín, M. (2011), Una galería de retratos reales: los soberanos omeyas de al-Ándalus (siglos II/ VIII-IV/X) en la cronística árabe. Anvario de Estudios Medievales 41/1, enero-junio de 2011 pp. $273-290$

Navarro Palazón, J. (1980), Cerámica musulmana de Murcia (España) con representaciones humanas. In La céramique médiévale en 
Méditerranée occidentale $X-X V$ siècles Valbonne, 1978. (317-320). Paris.

Navarro Palazón, J. (1986), La cerámica esgrafiada andalusí de Murcia. Madrid: Publications de la Casa de Velázquez.

Paulo, L. C. (2007), O simbolismo da purificação. O "Vaso de Tavira": iconografia e interpretação. Revista Portuguesa de Arqueologia. Lisboa: Instituto Português de Arqueologia. Vol. 10/1, 289-316.pdf.

Peral Bejarano, C. \& López Chamizo, S. (2006) Aproximación al juguete en su contexto arqueológico en Málaga. In Del rito al juego. Juguetes y silbatos de cerámica desde el Islam hasta la actualidad. Diciembre 2006 Febrero 2007. Museo de Almería. Catálogo de la exposición (111-131). Almería: Junta de Andalucía. Consejería de Cultura.

Prado-Vilar, F. (1997), Circular visions of fertility punishment: Califal ivory casketts from alAndalus. Muqarnas. Leiden, Brill. 14, 19-41.

Real, M. L. (1998), 18. Friso ornamental; 19. Pilar; 21 Pilar. In Portugal Islâmico. Os últimos sinais do Mediterrâneo $(82,83,85)$. Lisboa: Instituto Português de Museus.

Retuerce, M. \& Juan, A. de (1999), La cerámica almohade en verde y manganeso de la meseta. Arqueología y territorio medieval. Jaén: Universidad de Jaén. № 6, 241-260.

Retuerce, M. \& Zozaya, J. (1986), Variantes geográficas de la cerámica omeya andalusí: los temas decorativos. In La ceramica medievale nel Mediterraneo occidentale, Siena-Faenza, 1984 (69-128). Firenze.

Rodriguéz Zahar, L. (2008), Arte islámico, evocación del paraíso: doctrina, lenguaje y temas iconográficos. México: El colegio de México. Centro de Estudios de Asia y África. Disponible en http://books.google. $\mathrm{pt} /$ books?id=CG_xD8wXyMUC\&pg=PA71 \& pg=PA71 \&dq=dios+y+el+arte+evocación+ del+Paraiso \&source $=$ bl\&ots $=L$ tsw9ZICp0\&sig =vPTdLkCmptXaJpPvAYqo6u-pgXw\&hl=ptPT\&sa $=X \&$ ei=nevqUtf5FuOc0QXo8oHgBA\&ve

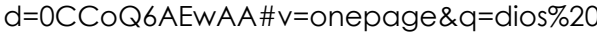
y\%20el\%20arte\%20evocación\%20del\%20 Paraiso \& $\mathrm{f}=$ false

Rosselló-Bordoy, G. (1992), Botella de los músicos. In Al-Andalus. Las artes islámicas en España (233). Madrid: El Viso.

Rosselló-Bordoy, G. (2006), El largo camino de una investigación. In Del rito al juego. Juguetes y silbatos de cerámica desde el Islam hasta la actualidad. Diciembre 2006 - Febrero 2007.
Museo de Almería. Catálogo de la exposición (p. 13-47). Almería: Junta de Andalucía. Consejería de Cultura.

Salinas Pleguezuelo, E. (2012), La cerámica tardoislámica de Madinat Qurtuba: Cronotipología y centros de producción (1031-1236 d.C.). Tesis doctoral. Córdoba: Universidad de Córdoba. Disponible en http:// helvia.uco.es/xmlui/handle/10396/7830.

Silva Santa-Cruz, N. (2013), La Eboraria Andalusí: Del Califato Omeya a la Granada Nazari. British Archaeological Reports International Series.

Soler, $M^{a}$ P. (2001), Zafa con figura de bebedor. In El esplendor de los Omeyas cordobeses. Catálogo de Piezas (174). Granada: El Legado Andalusí.

Soustiel, J. (1985), La céramique islamique. Fribourg: Office du Livre.

Tait, H. (1955), Pilgrim-Signs and Thomas, Earl of Lancaster. The British Museum Quarterly. Vol. 20, No. 2 (Sep., 1955), pp. 39-47.

Torres, C. (2004), O Vaso de Tavira, Una proposta de interpretação. Mértola: Campo Arqueológico de Mértola, 2004.

Torres, C. et alii (1996), Técnicas e utensílios de conservação dos alimentos na Mértola islâmica. Arqueologia Medieval. Porto: Edições Afrontamento. $N^{\circ}$ 4, 203-218.

Torres Balbás, L. (1956), Animales de juguete. Al-Andalus. Madrid - Granada. Vol. XXI, pp. 373-375.

VV. AA. (1993), Vivir en al-Andalus. Exposición de cerámica (s. IX-XV). Almería: Instituto de Estudios Almerienses, Almediterránea.

VV.AA. (1998). Portugal Islâmico. Os últimos sinais do Mediterrâneo. Lisboa: Instituto Português de Museus.

VV.AA. (2006). Del rito al juego. Juguetes y silbatos de cerámica desde el Islam hasta la actualidad. Diciembre 2006 - Febrero 2007. Museo de Almería. Catálogo de la exposición. Almería: Junta de Andalucía. Consejería de Cultura.

Zozaya, J. (2010), Militares en iluminaciones y marfiles: una visión del ejército califal. Cuadernos de Madinat Al-Zahra. N N 7, 43-63.

Zozaya, J. (2011), Símbolos. In Gómez Martínez, S. (Ed.) Os Signos do Quotidiano: Gestos, Marcas e Símbolos no al-Ândalus. Catálogo da Exposição (9-21). Mértola: Campo 
Susana Gómez Martínez

Arqueológico de Mértola. 